\title{
PRODUKSI ENBAL (SINGKONG) CRISPY YANG DIFORTIFIKASI SERAT RUMPUT LAUT
}

\author{
Ismael Marasabessy'1), Fien Sudirjo1), Syahibul K. Hamid1), \& Yuni Irmawaty2) \\ 1)Jurusan Teknologi Hasil Perikanan, \\ 2)Jurusan Bioteknologi Perikanan, \\ Politeknik Perikanan Negeri Tual \\ ismael mabes@yahoo.com
}

\begin{abstract}
Abstrak
Tujuan umum kegiatan ini adalah mengembangkan budaya knowledge based economy dalam bidang usaha pengolahan berbasis pangan lokal enbal (singkong) dan rumput laut dengan memanfaatkan pengetahuan, pendidikan maupun hasil riset. Tujuan khusus yaitu memaksimalkan penggunaan rumput laut sebagai sumber serat untuk bahan fortifikan agar dapat meningkatkan daya saing (nilai ekonomi dan nilai gizi) enbal crispy sebagai pangan lokal masyarakat kepulauan Kei. Metode pelaksanaan program ini dilakukan dalam tiga tahap. Tahap pertama dilakukan produksi rumput laut dengan umur panen 60 hari. Tahap kedua diproduksi tepung enbal (singkong) dengan metode press ulir. Tahap ketiga di lakukan produksi enbal crispy rumput laut (ECRL). Hasil kegiatan menunjukkan produk ECRL cukup diminati konsumen, baik lokal maupun luar Maluku. Selama 6 bulan, produksi rumput laut sebanyak $500 \mathrm{~kg}$ (70\%), produksi tepung enbal sebanyak $20 \mathrm{~kg}$ (40\%), produksi ECRL yang dihasilkan sebanyak 800 dos (20\%), pendapatan mencapai $36 \%$ dari target yang telah ditetapkan. Enbal crispy yang dihasilkan mengandung kadar air $8 \%$ dan $\mathrm{HCN}<3 \mathrm{mg} / \mathrm{kg}$.
\end{abstract}

Kata Kunci: enbal, crispy, rumput laut, daya saing.

\section{PENDAHULUAN}

Masyarakat kepulauan Kei (Maluku Tenggara) mempunyai pangan lokal yang sudah lama dikenal sebagai pangan pengganti nasi yakni "enbal" (singkong dengan kadar HCN tinggi). Saat ini enbal telah dimodifikasi dan banyak dijual sebagai cemilan atau makanan pendamping teh dan kopi. Produk ini mempunyai peluang besar untuk dikembangkan sebagai ciri khas daerah jika didiversifikasi menjadi pangan sehat yang bergizi karena peminatnya cukup banyak. Hasil penelitian Tapotubun (2010, 2012) dan Marasabessy et al, (2014) menunjukkan kandungan gizi enbal lempeng sangat terbatas masih perlu ditingkatkan lagi terutama untuk serat dan mineral.
Sebagai makanan khas daerah, enbal dikonsumsi oleh semua lapisan masyarakat. Makanan ini dihidangkan dengan berbagai macam cara yakni disangrai yang disebut enbal goreng, didadar disebut enbal bubuhuk dan dibakar disebut enbal bubes (porna). Enbal crispi merupakan salah satu hasil diversifikasi yang akhir-akhir ini marak diproduksi sebagai oleh-oleh khas daerah dan cukup diminati oleh masyarakat lokal maupun dari luar Kei. Faktor yang memperngaruhi kualitas enbal crispi antara lain formula bahan, teknik pengeringan dan teknik pemanggangan.

Produksi rumput laut Kepulauan Kei dalam 5 tahun terakhir cukup tinggi dan terus mengalami peningkatan (DKP Malra, 2015). 
Kondisi ini menyebabkan penyediaan serat yang berasal dari rumput laut cukup besar. Serat sangat penting dalam proses pencernaan makanan di tubuh. Kekurangan serat dapat menyebabkan konstipasi, apenaistis, alverculity, hemoroid, diabetes melitus, penyakit jantung koroner dan batu ginjal (Almatsier, 2009). Secara tradisional rumput laut telah lama digunakan sebagai bahan makanan dan obat-obatan karena kaya akan mineral, elemen makro dan elemen mikro lainnya. Beberapa jenis rumput laut mengandung mineral penting yang berguna untuk metabolisme tubuh seperti iodin, calsium, selenium, dan serat (Burtin, 2006). Agar pemanfaatan rumput laut dapat lebih maksimal sebagai sumber serat, serta disisi lain ada peningkatan kualitas pangan lokal maka perlu dilakukan diversifikasi produk yakni dengan melakukan fortifikasi rumput laut ke dalam enbal serta membuatnya lebih diterima masyarakat luas sebagai cemilan oleh oleh khas Kepulauan Kei.

Tujuan umum kegiatan ini adalah mengembangkan budaya knowledge based economy dalam bidang usaha pengolahan berbasis pangan lokal enbal (singkong) dan rumput laut dengan memanfaatkan pengetahuan, pendidikan maupun hasil riset. Tujuan khusus yaitu memaksimalkan penggunaan rumput laut sebagai sumber serat untuk bahan fortifikan agar meningkatkan daya saing (nilai ekonomi dan nilai gizi) enbal crispy sebagai pangan lokal masyarakat kepulauan Kei.

\section{METODE PELAKSANAAN}

\section{Waktu dan Tempat}

Kegiatan dilakukan selama 4 bulan yang berlokasi pada tiga tempat. Pelaksanaan budidaya rumput laut dilakukan di perairan dekat dermaga kampus Politeknik Perikanan Negeri Tual, desa Sathean Kabupaten Maluku Tenggara. Sementara pengolahan ECRL dilakukan di laboratorium Pengolahan Ikan Politeknik Perikanan Negeri Tual, dan analisis kualitas ECRL dilakukan di laboratorium Balai Besar Industri Agro Bogor.

\section{Bahan dan Alat}

Bahan untuk budidaya rumput laut terdiri dari tali nilon, pelampung bola fiber, bibit dan rumput laut, bahan baku utama untuk pembuatan ECRL yaitu rumput laut jenis Eucheuma cottonii dan enbal/singkong (Manihot sp.), serta bahan tambahan meliputi telur, mentega, susu dan gula.

\section{Prosedur Kegiatan}

Kegiatan terdiri dari tiga tahap. Tahap I produksi rumput laut yang dibudidaya dengan metode longline selama 60 hari. Tahap kedua produksi tepung enbal/singkong yang akan digunakan sebagai bahan baku ECR. Tahap ketiga dilakukan fortifikasi rumput laut pada enbal lempeng, kemudian dianalsis kandungan HCN dan kadar air. Tahapan kegiatan sebagai berikut:

- Budidaya rumput laut. Bibit rumput laut yang digunakan adalah bagian thallus 
muda berkualitas baik dengan panjang 10-15 cm, biomass awal $150 \mathrm{~g}$, menggunakan metode rawai atau long line. Sebanyak 3 long line digunakan untuk mengikat bibit dengan panjang satu long line $10 \mathrm{~m}$. Jarak antara long line $120 \mathrm{~cm}$ dan jarak antar bibit $30 \mathrm{~cm}$. Pada tiap sudut dan bagian tengah tali dipasang pelampung utama serta pemberat. Bibit E. cottonii diusahakan selalu berada dibawah permukaan air. Panen dilakukan saat rumput laut berumur 60 hari;

- Pembuatan bubur rumput laut. Bubur rumput laut dibuat dengan cara rumput laut kering direndam dengan air beras sampai agak lembek dan hilang bau amis, kemudian dipanaskan selama kurang lebih 10 menit lalu diblender hingga menjadi bubur;

- Pembuatan tepung enbal/singkong. Enbal/singkong yang tinggi kadar HCN dikupas dan dicuci kemudian diparut menggunaan mesin. Hasil parutan diperas menggunakan alat pres ulir hingga kadar air berkurang. Selanjutya digiling menjadi tepung dan diayak sehingga diperoleh tepung enbal yang halus dan putih;

- Produksi enbal lempeng. Tepung enbal ditata dalam porna/cetakan ukuran $3 \mathrm{x}$ 4,5 cm kemudian di panggang selama kurang lebih 10 menit sehingga terbentuk enbal lempeng yang kaku dan kompak; dan
- Produksi enbal crispy rumput laut. Bubur rumput laut 15\% dicampurkan kedalam adonan (campuran bahanbahan tambahan) lalu dimixer sampai tercampur merata. Kemudian adonan dioleskan pada permukaan enbal lempeng, selanjutnya dipanggang dalam oven sampai matang.

\section{HASIL DAN PEMBAHASAN}

\section{Produksi Rumput Laut Segar}

Sesuai dengan prosedur kerja budidaya rumput laut jenis E. cottonii, setiap 60 hari dilakukan panen rumput laut. Teknik panen yang dgunakan adalah panen full dengan melepaskan tali ris kemudian dijemur diatas para-para penjemuran. Umur panen 60 hari ditentukan berdasarkan hasil penelitian (Marasabessy et al., 2017) yang telah dilakukan sebelumnya, dimana rumput laut yang dipanen lebih 60 hari mengalami penurunan kandungan serat. Rumput laut yang dipanen sebagian digunakan sebagai bahan fortifikan dalam produksi enbal crispy rumput laut dan sebagian dijual. Proses panen rumput laut di tampilkan pada Gambar 1. Rumput laut $E$. cottonii kemudian dikeringkan selama kurang lebih 2 hari untuk mendapatan rumput laut kering dengan kadar air sekitar 25\%. Menurut Standar Nasional Indonesia (1992) kandungan air pada rumput laut kering maksimal 35\%. Selama 6 bulan kegiatan, produksi rumput laut mencapai 
Jurnal ABDIMAS, Vol. 11, No. 3, Desember 2018

ISSN: 1979-0953 | e-ISSN: 2598-6066

$500 \mathrm{~kg}$ atau $70 \%$ dari target yang telah ditetapkan.
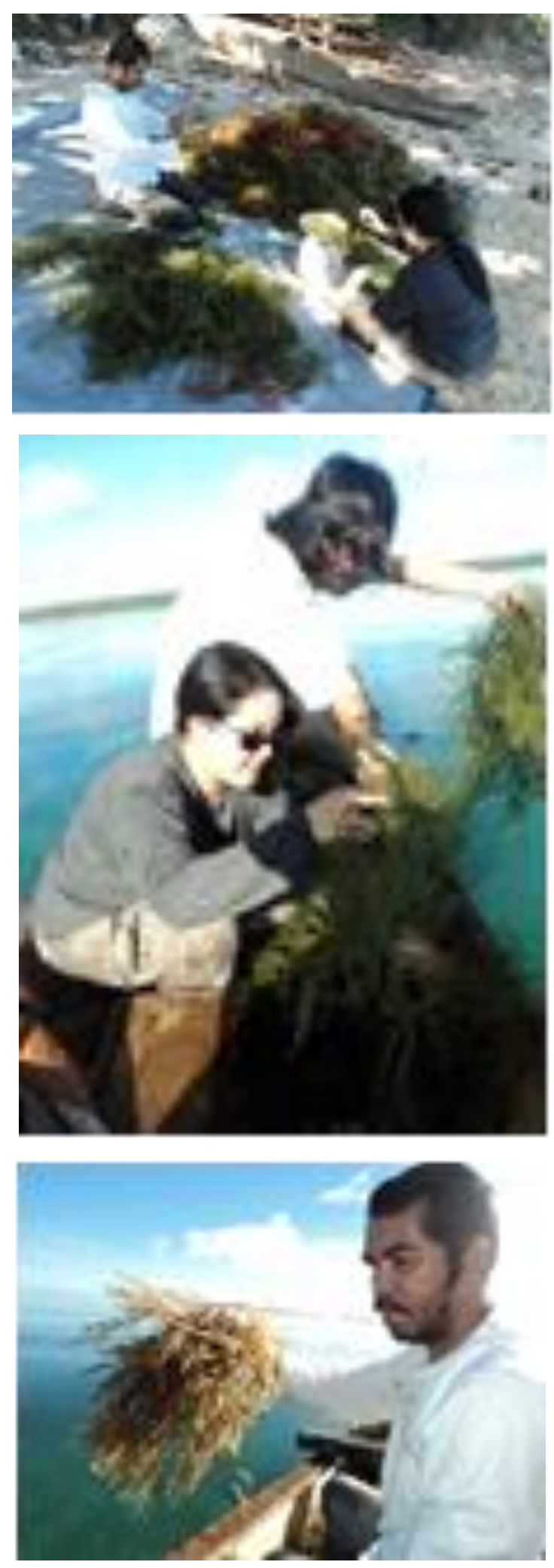

Gambar 1. Proses panen rumput laut E. cotonii.

\section{Produksi Bubur Rumput Laut}

Bahan baku rumput laut yang digunakan sebagai bahan fortifikan untuk enbal crispy rumput laut harus menggunakan bubur rumput laut. Hasil penelitian Marasabessy et al., (2017) menunjukkan bahwa bubur rumput laut yang di tambahkan ke dalam enbal/singkong lempeng lebih disukai panelis.
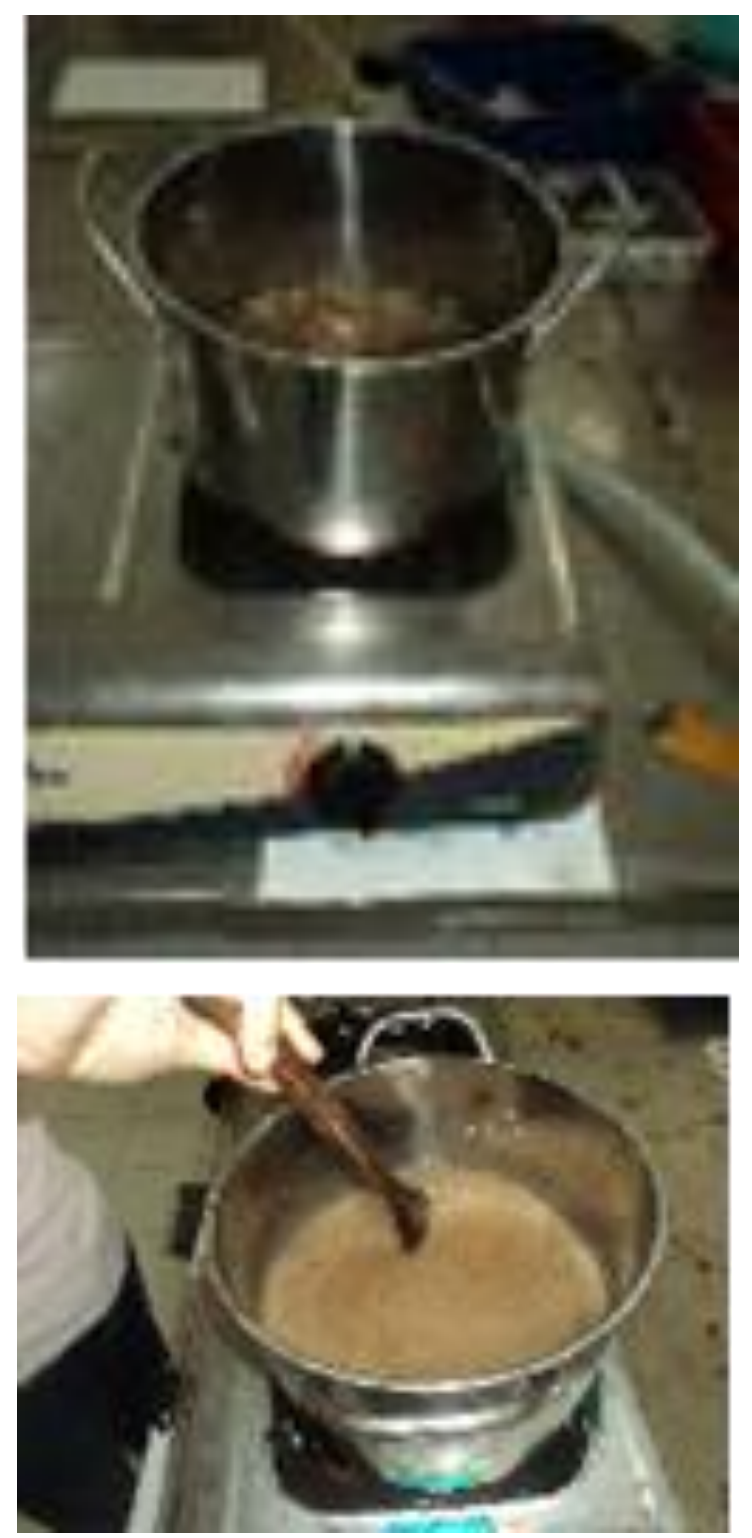

Gambar 2. Pembuatan bubur rumput laut. 


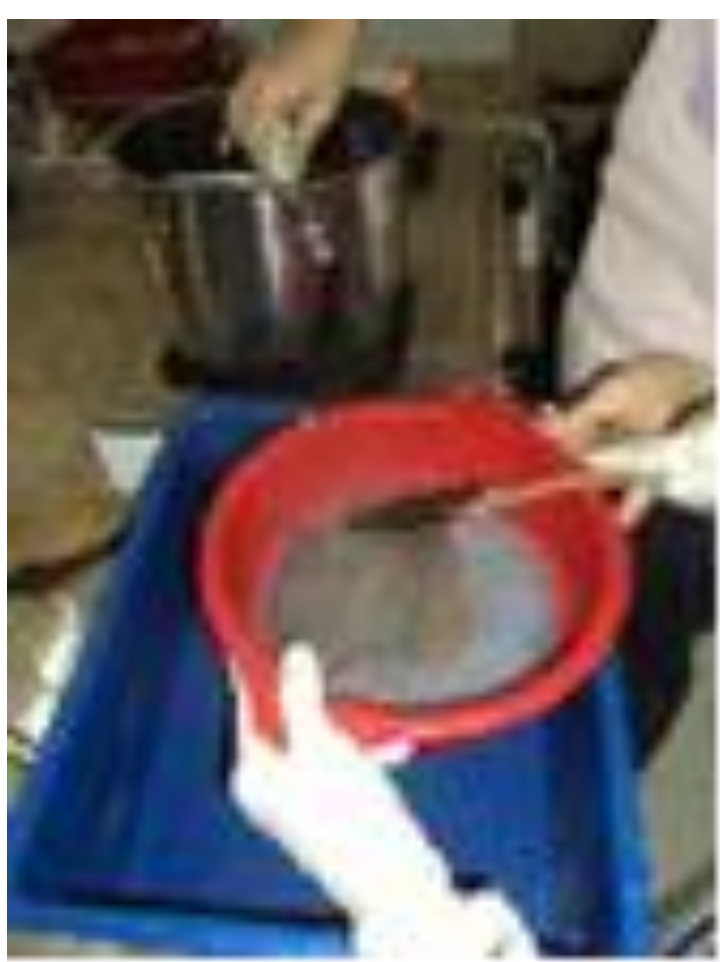

Gambar 2 (lanjutan). Pembuatan bubur rumput laut.

Rumput laut kering direndam selama kurang lebih 2 hari menggunakan air cucian beras. Rumput laut sudah bisa digunakan jika bau amis sudah hilang serta teksturnya sudah agak lembek yang ditan-dai dengan mudah diputuskan batangnya dengan kuku atau dengan jari. Proses perebusan rumput laut dilakukan dengan menambahkan sedikit air dalam panci yang telah dimasukkan rumput laut. Perebusan dilakukan selama kurang lebih 10 menit sampai air mendidih (Gambar 2). Hal ini dimaksudkan untuk membunuh bakteri yang ada di rumput laut serta mudah di campurkan dengan bahan tambahan lainnya. Bubur rumput laut yang dihasilkan selanjutnya disaring sehingga diperoleh bubur rumput laut halus yang siap digunakan. Penyaringan menggunakan ayakan dengan mesh size $60 \mu \mathrm{m}$.

\section{Produksi Tepung Enbal/Singkong}

Enbal/singkong yang digunaan dalam produksi enbal crispy rumput laut mempunyai kandngan HCN yang tinggi yaitu lebih dari 100 mg/kg. Dengan kadar HCN seperti ini, enbal tidak bisa langsung dikonsumsi karena bisa menyebabkan kematian. Standar mutu tepung singkong (SNI, 1992) maksimum $40 \mathrm{mg} / \mathrm{kg}$, tepung mocaf (SNI, 2011) maksimum $10 \mathrm{mg} / \mathrm{kg}$ serta standar FAO kurang dari $50 \mathrm{mg} / \mathrm{kg}$ umbi kering. Penggunaan alat pres ulir pada produksi tepung enbal dalam kegiatan ini sangat bermanfaat dalam menurunkan kadar HCN menjadi sangat rendah. Dengan berkurangnya kadar air yang cukup besar yaitu sekitar $6 \%$, menyebabkan kandungan HCN juga sangat berkurang yakni menjadi $<0,3 \mathrm{mg} / \mathrm{kg}$ sehingga sangat aman untuk dikonsumsi.

Enbal yang telah di parut, diperas dalam alat pres ulir. Dandang berlubang digunakan sebagai tempat menaruh enbal parutan yang memudahkan keluarnya air saat alat press hidrolik bekerja. Penggunaan dongkrak dengan kapasitas 3 ton banyak membantu pengurangan kadar air dan kadar HCN. Enbal yang telah di press kualitasnya jauh lebih baik dibanding hasil produksi masyarakat, dimana teksturya sangat kering dan bau asamnya hampir tidak tercium lagi. Enbal yang telah kering 
kemudian digiling menggunakan mesin sehingga diperoleh tepung enbal yang putih, kemudian diayak dengan ayakan mesh size $60 \mu \mathrm{m}$ agar diperoleh tepung enbal yang putih dan halus (Gambar 3). Selama 6 bulan kegiatan, produksi tepung enbal mencapai $20 \mathrm{~kg}$ atau $40 \%$ dari target yang telah ditetapkan.
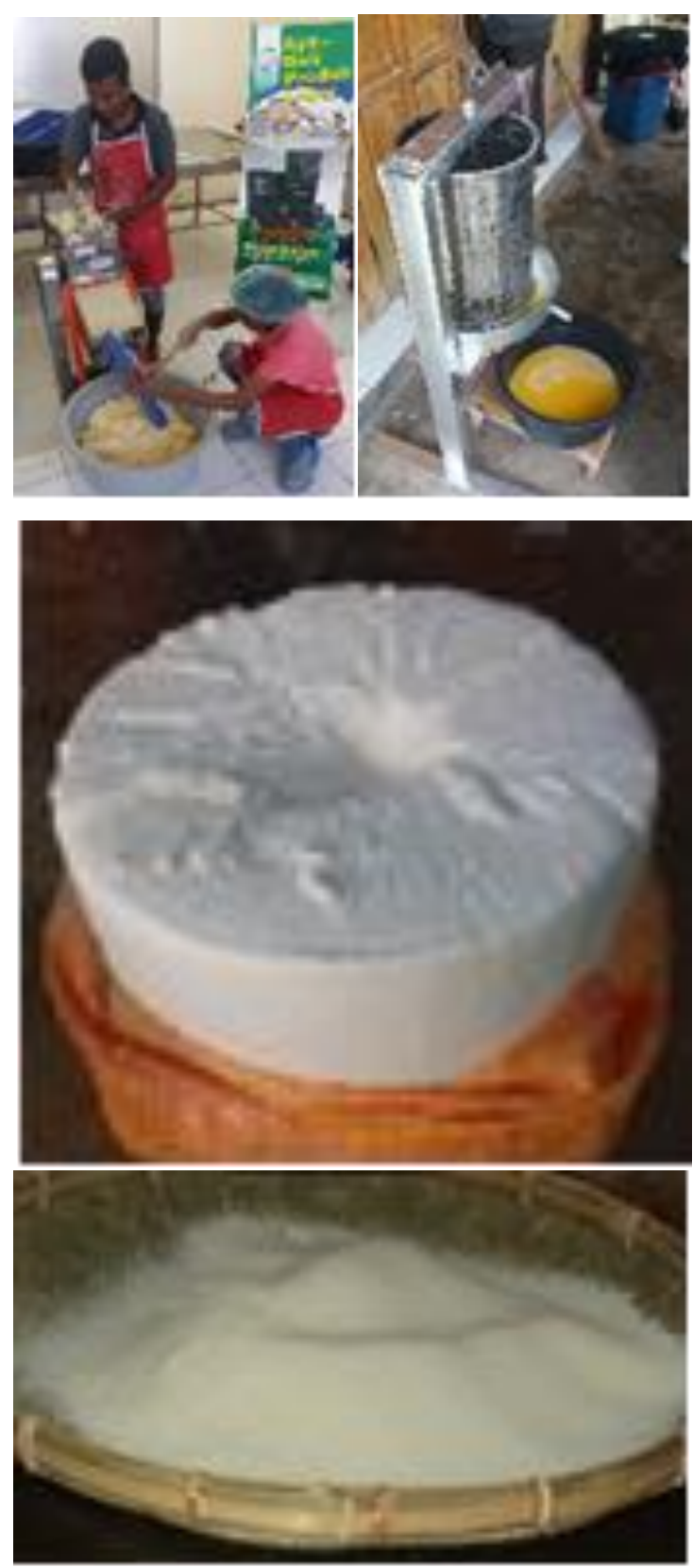

Gambar 3. Produksi tepung enbal.

\section{Produksi Enbal Lempeng}

Tepung enbal yang telah dicetak menjadi enbal lempeng berbentuk empat persegi dengan ukuran $3 \times 4,5 \mathrm{~cm}$. Proses pemanggangan dilakukan selama lebih kurang 10 menit agar tepung menjadi kompak dan proses pematangan merata (Gambar 4). Penggunaan api yang tidak terlalu besar membantu pembentukan tekstur enbal lempeng tetapi tidak menjadi hangus. Selanjutnya enbal lepeng di jemur agar teksturnya lebih kompak serta tidak mudah patah saat kering.
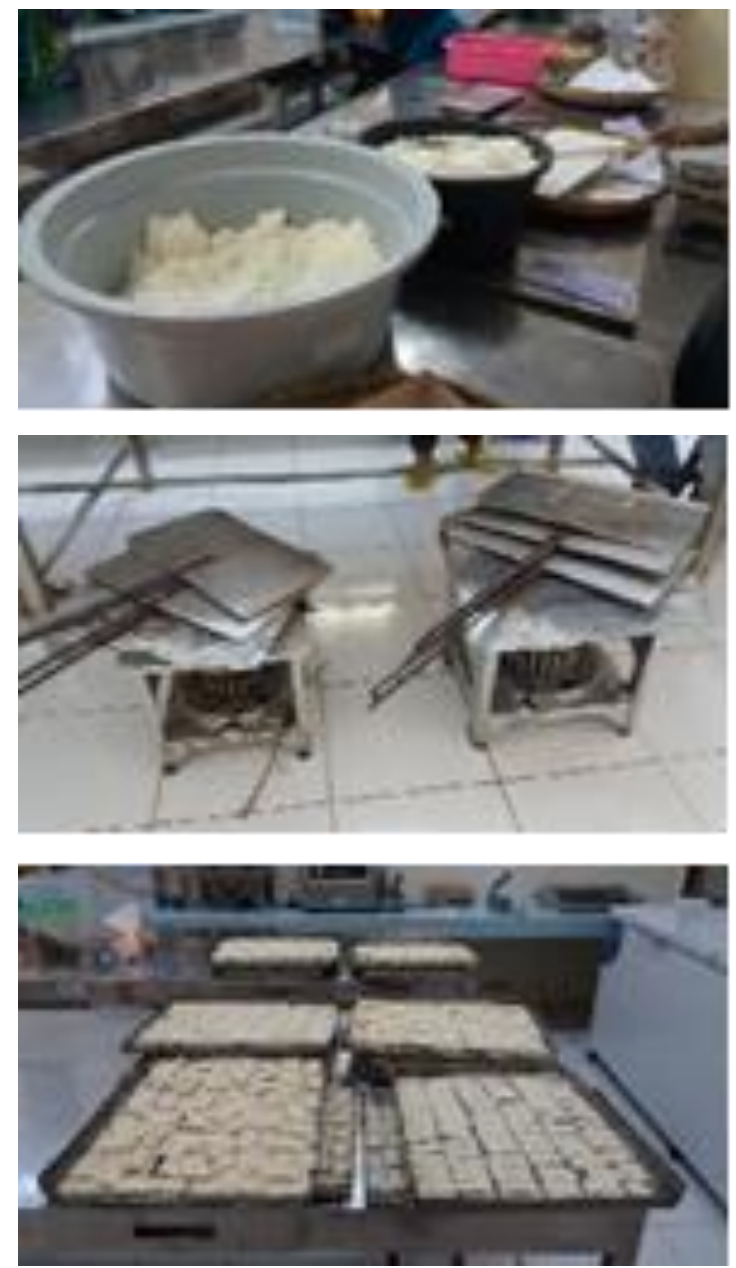

Gambar 4. Produksi enbal lempeng. 


\section{Produksi Enbal Crispy Rumput Laut (ECRL)}

Enbal crispy rumput laut di produksi dengan mencampurkan semua bahan tambahan dengan bubur rumput laut yang telah di saring. Proses pencamuran menggunakan mixer sehingga adonan lebih kalis. Dilanjutkan dengan pengolesan adonan pada permukaan enbal. Enbal crispy yang baik harus seluruh permukaan ditutupi adonan agar rasa lebih merata. Selanjutnya dipanggang dalam oven dengan api kecil. Penggunaan api kecil dimaksudkan agar produk tidak hangus dan proses pematangan lebih merata. Pemanggangan dilakukan selama $10-13$ menit.
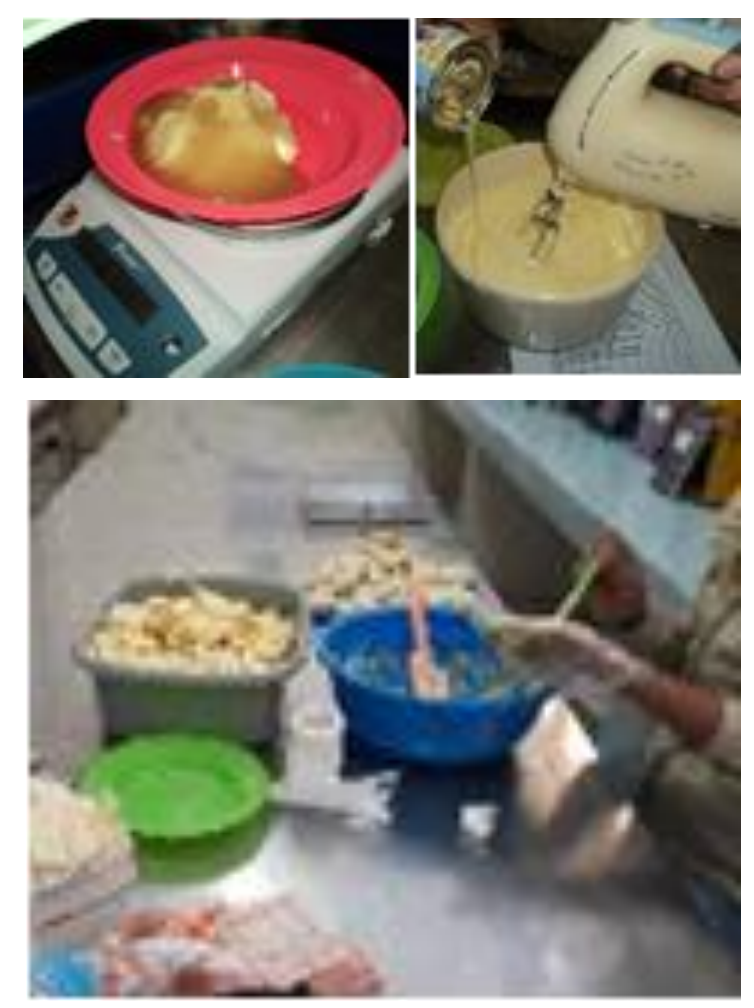

Gambar 5. Proses produksi enbal crispy rumput laut.
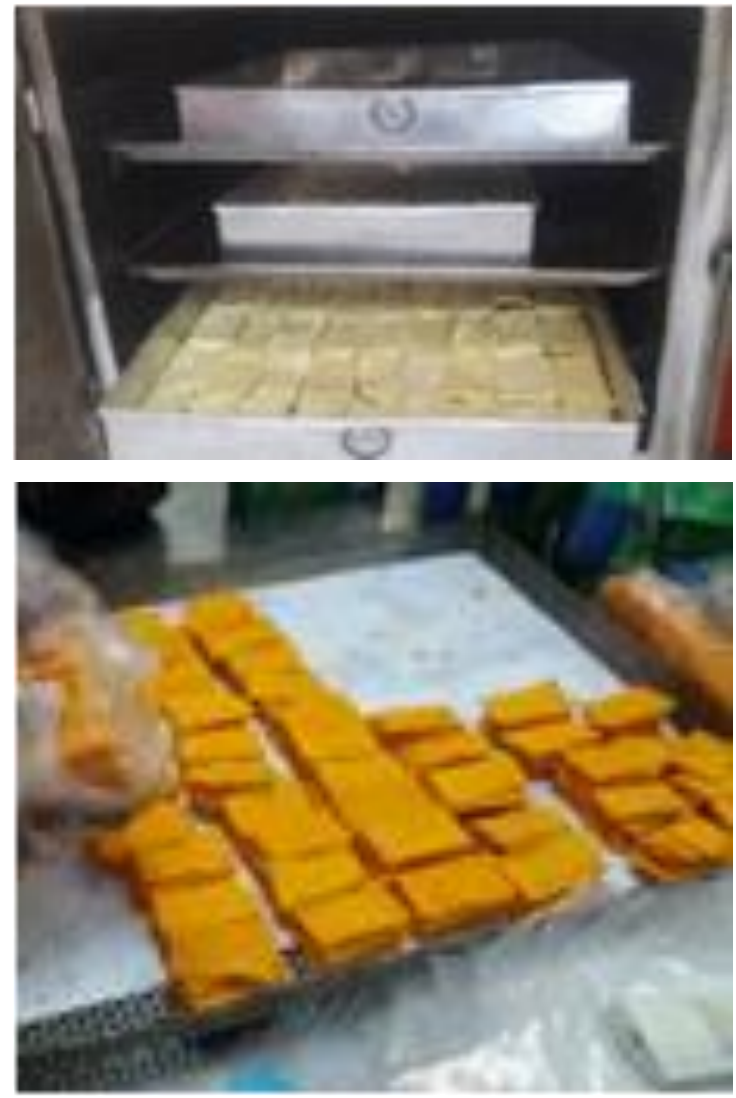

Gambar 5 (lanjutan). Proses produksi enbal crispy rumput laut.

Enbal crispy rumput laut yang diproduksi cukup diminati konsumen, baik lokal maupun luar Maluku. Hal ini karena rasanya yang gurih dan crispy sehingga enak di mulut. Selama 6 bulan ECRL yang dihasilkan sebanyak 800 dos atau 20\% dari total produksi, pendapatan mencapai $36 \%$ dari target yang ditetapkan. Enbal crispy yang dihasilkan mengandung kadar air 7\% dan $\mathrm{HCN}<3 \mathrm{mg} / \mathrm{kg}$ sehingga aman dikonsumsi.

\section{KESIMPULAN DAN SARAN}

\section{Kesimpulan}

1. Enbal crispy rumput laut cukup diminati konsumen baik lokal maupun luar 
Maluku. Kegiatan selama 6 bulan menghasilkan rumput laut segar sebanyak $500 \mathrm{~kg}$ (70\%), produksi tepung enbal sebanyak $20 \mathrm{~kg}$ (40\%), produksi ECRL sebanyak 800 dos (20\%), pendapatan mencapai $36 \%$ dari target yang telah ditetapkan; dan

2. Enbal crispy yang dihasilkan mengandung kadar air 8\% dan $\mathrm{HCN}<3$ $\mathrm{mg} / \mathrm{kg}$ sehingga aman dikonsumsi.

\section{Saran}

Perlu ditingkatkan strategi pemasaran agar pendapatan makin optimal.

\section{UCAPAN TERIMA KASIH}

Terima kasih disampaikan kepada Direktorat Riset dan Pengabdian Kepada Masyarakat, Kemristekdikti RI yang telah membiayai kegiatan PPUPIK tahun 2018 ini.
International. Gaithersburg, Maryland. USA.

Almatsier S.,2009. Prinsip Dasar Ilmu Gizi. PT Gramedia Pustaka Utama, Jakarta.

Burtin P., 2006. Nutritional Value of Seaweed. Electronic J. Environ. Agric. Food J. Chem. 5 (3).

DKP Malra, 2015. Laporan Tahunan.Dinas Kelautan dan Perikanan Kabupaten Maluku Tenggara.

Marasabessy I, Sudirjo F., 2017. Seaweed Fortification on Crispy Enbal as Local Food of Kei Islands. IOP Conf. Series: Earth and Environmental Science. Vol 89.

Sitepu JM., 2009. Pengaruh Waktu Perendaman Terhadap Penurunan Kadar Asam Sianida (HCN) Pada Ubi Kayu Pahit (Manihot esculentaGrant). [17 Januari 2012].

SNI [1992]. Syarat Mutu Tepung Ubi Kayu. Standar Nasional Indonesia Nomor 012997-1992. Badan Standarisasi Nasional. Republik Inddonesia.

SNI [2011]. Tepung Mocaf. Badan Standar Nasional. Jakarta

\section{KEPUSTAKAAN}

AOAC., 2005. Official Methods of Analysis of AOACInternational. Published by AOAC 